\title{
INOVAÇÕES TECNOLÓGICAS, EDUCAÇÃO E NECESSIDADES DO CAPITAL
}

\author{
INNOVACIONES TECNOLÓGICAS, EDUCACIÓN Y NECESIDADES DEL \\ CAPITAL
}

TECHNOLOGICAL INNOVATIONS, EDUCATION AND CAPITAL NEEDS

\author{
Maria das Graças de Almeida BAPTISTA ${ }^{1}$ \\ Tânia Rodrigues PALHANO² \\ Ercules Laurentino DINIZ ${ }^{3}$ \\ Genilson José da SILVA ${ }^{4}$
}

RESUMO: O presente trabalho tem como objetivo retomar a discussão acerca do denominado "Livro Verde", como exemplo da adesão do Brasil a um ideário educacional sintonizado com o desenvolvimento atual da sociedade capitalista. O estudo toma como pressuposto que o desenvolvimento tecnológico se insere no processo de desenvolvimento da própria sociedade capitalista e possibilita afirmar que os questionamentos acerca da informação e da tecnologia têm se restringido à sua aplicabilidade, ao seu uso e a uma crescente e permanente reflexão em relação ao aumento da exclusão da maioria da população do acesso às tecnologias digitais. Assim, a educação, e mais especificamente a escola, é chamada a exercer esse papel de conformação e adaptação a uma dada realidade: a sociedade capitalista.

PALAVRAS-CHAVE: Tecnologias digitais. Educação. Capitalismo.

RESUMEN: El presente trabajo tiene como objetivo retomar la discusión acerca del denominado "Libro Verde", como ejemplo de la adhesión del Brasil a un ideario educacional sintonizado con el desarrollo actual de la sociedad capitalista. El estudio toma como presupuesto que el desarrollo tecnológico se insiere en el proceso de desarrollo de la propia sociedad capitalista y posibilita afirmar que los cuestionamentos acerca de la información y

${ }^{1}$ Universidade Federal da Paraíba (UBPB), João Pessoa - PB - Brasil. Pós-doutorado em Educação pela Universidade Estadual de Campinas (UNICAMP), Doutorado e Mestrado em Educação pela Universidade Federal da Paraíba (UFPB). Professora Associada de Psicologia da Educação do Centro de Educação da UFPB e Docente do Programa de Pós-graduação em Educação (PPGE). OrcID: https://orcid.org/0000-0003-1084-4269. E-mail: mgabaptista2@yahoo.com.br

${ }^{2}$ Universidade Federal da Paraíba (UBPB), João Pessoa - PB - Brasil. Pós-doutorado em Educação pela Universidade Estadual de Campinas (UNICAMP), Doutorado e Mestrado em Educação pela Universidade Federal da Paraíba (UFPB). Professora Associada de Filosofia da Educação do Centro de Educação da UFPB e Docente do Programa de Pós-graduação em Educação (PPGE). OrcID: http://orcid.org/0000/0003/3573/6889. Email: taniarpalhano@gmail.com

${ }^{3}$ Universidade Federal da Paraíba (UBPB), João Pessoa - PB - Brasil. Doutorando em Educação pelo Programa de Pós-graduação em Educação (PPGE). OrcID: https://orcid.org/0000-0003-4932-8915. E-mail: ercules.diniz@hotmail.com

${ }^{4}$ Universidade Federal da Paraíba (UBPB), João Pessoa - PB - Brasil. Mestre em Educação pelo Programa de Pós-graduação em Educação (PPGE). OrcID: http://orcid.org/0000-0003-0983-7029. E-mail: genilsonjos27@gmail.com 
de la tecnología se tienen restringido a su aplicabilidad, a su uso y a una creciente y permanente reflexión respecto al aumento de la exclusión de la mayoría de la población del acceso a las tecnologías digitales. Así, la educación, y más específicamente la escuela, es llamada a ejercer ese papel de conformación y adaptación a una dada realidad: la sociedad capitalista.

PALABRAS CLAVE: Tecnologias digitales. Educación. Capitalismo.

ABSTRACT: This paper aims to retake the discussion about the called "Green Book" as an example of Brazil's adherence to an educational ideology in tune with the current development of capitalist society. The study assumes that technological development is inserted in the process of development of capitalist society itself and makes it possible to affirm that questions about information and technology have been restricted to its applicability, its use and to a growing and permanent reflection regarding the increasing exclusion of the majority of the population from access to digital technologies. Thus, education, and more specifically the school, is called to play this role of conformation and adaptation to a given reality: capitalist society.

KEYWORDS: Digital technologies. Education. Capitalism.

\section{Introdução}

O presente trabalho tem como objetivo retomar a discussão acerca do denominado "Livro Verde", como exemplo da adesão do Brasil ao ideário educacional sintonizado com o desenvolvimento atual da sociedade capitalista.

O estudo adota como referencial teórico o materialismo histórico e dialético por compreender que o mesmo se caracteriza como a possibilidade de análise e transformação da realidade, a partir das contradições inerentes a essa realidade. Com base no materialismo histórico, as inovações tecnológicas são analisadas a partir do modo de produção dos bens materiais, ou seja, enquanto determinadas pelas condições da vida material da sociedade, a tempo em que determina as condições materiais da vida social.

Nesse estudo, a escolha método implica, segundo Gamboa (1989, p. 33) ${ }^{5}$, tomar como ponto de partida as reflexões sobre a relação desenvolvimento capitalista e suas implicações na educação, afirmando a unidade entre o econômico e o político; "passar pelo abstrato", a análise do desenvolvimento das tecnologias digitais e a propalada "crise dos paradigmas"; e "formar uma nova síntese" que se refere à discussão da relação entre as inovações tecnológicas e a educação, materializada no "Livro Verde".

\footnotetext{
${ }^{5}$ A esse respeito ver também Gamboa (1998, p. 32).
} 
Além desses aspectos, toma-se como pressupostos, primeiro, que o desenvolvimento tecnológico está no cerne do processo de desenvolvimento da sociedade capitalista, enquanto força produtiva, instrumento de produção, elemento determinante do desenvolvimento da produção e de toda a sociedade. A propriedade privada desses meios obriga os homens a vender a sua força de trabalho, definindo as relações de produção. Outro pressuposto é o de que a educação escolar, nesse processo de desenvolvimento capitalista, exerce um relevante papel, uma vez que tem sido historicamente chamada a formar os quadros necessários a esse desenvolvimento, conformando-os às relações sociais de produção.

Com o avanço tecnológico, a escola é chamada a desenvolver competências e habilidades necessárias à reprodução do capital, havendo "apenas lugar para os mais 'competentes', ou que desenvolvem, ao longo de sua vida, aquelas qualidades técnicas e psicossociais que interessam ao mercado" (FRIGOTTO, 2015, p. 220), apontando o sujeito que não possui tais competências e habilidades como responsável pela sua exclusão do mercado de trabalho. Assim, torna-se imprescindível, para a compreensão de debates acerca do desenvolvimento tecnológico na atualidade, a análise de seu reflexo na educação e na manutenção da exclusão.

\section{Desenvolvimento capitalista, tecnologias digitais e a "crise de paradigmas"}

Em O Capital, Marx (1978, p. 130) afirma que a estrutura econômica determina o perfil de uma sociedade, apontando a existência de uma superestrutura necessária à manutenção dessa estrutura. Assim, as diferentes ideias e instituições políticas se explicam pelas diversas condições da vida material da sociedade, das quais são um reflexo, que têm como força principal "o modo de produção da vida material [que] condiciona o processo em geral de vida social, político e espiritual".

Há dois aspectos dialeticamente inseparáveis do modo de produção: as forças produtivas e as relações de produção. As forças produtivas (incluindo o próprio homem) são os instrumentos de produção necessários à produção dos bens materiais, o elemento determinante do desenvolvimento da produção. $\mathrm{O}$ outro aspecto, as relações de produção, são as relações entre os homens no processo de produção, que depende de com quem se encontram os meios de produção, de transporte, de comunicação, etc.

$\mathrm{Na}$ sociedade capitalista, os meios de produção se encontram na posse privada dos capitalistas, assim, ao caráter social do processo de produção se contrapõe a propriedade privada dos instrumentos de produção material e cultural. Marx, (2011, p. 943) sinaliza que 
"as forças produtivas e as relações sociais [...] aparecem somente como meios para o capital, e para ele são exclusivamente meios para poder produzir a partir de seu fundamento acanhado".

A relação dialética entre a estrutura, base material, e a superestrutura, ideologia, se firma uma vez que, com a transformação da base econômica, "toda a enorme superestrutura se transforma com maior ou menor rapidez" (MARX, 1978, p. 130). Assim, a cada mudança nos instrumentos e, consequentemente, na relação de produção, toda a produção material e ideológica é modificada, o que não ocorre sem conflitos.

As novas forças produtivas entram em contradição com as relações de produção e de propriedade existentes, que são suprimidas pelo papel imprescindível das novas ideias sociais, das novas instituições políticas, do novo poder político. Logo, torna-se necessário "distinguir sempre entre a transformação material das condições econômicas da produção [...] e as formas jurídicas políticas, religiosas, artísticas ou filosóficas".

Gramsci $(1989$, p. 49) acentua essa relação dialética entre a estrutura e a superestrutura (ideologia), apontando que o desenvolvimento de uma classe depende de uma formação "no terreno econômico [e um] desenvolvimento paralelo nos terrenos ideológico, jurídico, religioso, intelectual e filosófico". Logo, afirma que é a realidade social que cria as ideologias e não as ideologias que criam a realidade social e conclui que esse conjunto complexo das superestruturas é "contraditório e discordante", uma vez que reflete "o conjunto das relações sociais de produção", também contraditório (GRAMSCI, 1995, p. 262; 270; 52),

Para uma melhor compreensão dessa relação, torna-se necessário entender-se o conceito de "bloco histórico", que é formado por uma estrutura social (as classes relacionadas às forças produtivas) e uma superestrutura ideológica e política. Logo, uma classe que se torne dominante exerce um poder hegemônico sobre a outra, no nível econômico e no ideológico e político. Entretanto, a hegemonia é em si também contraditória, uma vez que se estabelece um consenso sobre o conjunto da sociedade.

No cárcere, o autor amplia o conceito de Estado (Integral) que passa a envolver tanto as funções da sociedade civil quanto as da sociedade política, o que pressupõe a ampliação do aparelho de Estado, “aparelho de governo' e "aparelho 'privado' de hegemonia" (GRAMSCI, 2007, p. 254-255), assim como a ampliação do conceito de intelectual, definido como grupos sociais que operam no nível superestrutural e têm por função organizar a hegemonia de um grupo (GRAMSCI, 1989, p. 3-4). O lugar do intelectual, portanto, deriva tanto das superestruturas como do aparelho de produção.

${ }^{6}$ Esse conceito surge com G. Sorel (1847-1922), mas é ampliado por Gramsci. A esse respeito ver Gramsci (1995, p. 263) e Simionatto (2004, p. 41). 
Os intelectuais exercem "funções subalternas da hegemonia social e governo político", assegurando a expansão dos diferentes aparelhos de hegemonia da classe dominante. $\mathrm{O}$ autor defende que o proletariado também deve criar seus próprios intelectuais, advertindo que os intelectuais representantes da classe dominante podem suscitar uma atração ("transformismo") nas demais camadas de intelectuais, levando à criação de um "bloco ideológico" (GRAMSCI, 1989, p. 3; 11; 139; 146). Logo, a hegemonia que nasce da fábrica não pode existir sem hegemonia fora da fábrica.

No Cárcere, Gramsci $(1995$, p. $14 ; 16 ; 258)$ aponta que a ideologia faz com que os sujeitos que pertencem a um determinado grupo compartilhem o modo de pensar e de agir. No bloco ideológico, a filosofia, enquanto expressão cultural da classe dominante, tem um papel essencial, ao influenciar a concepção de mundo e a vida de todas as camadas sociais. Por outro lado, o senso comum, enquanto "amálgama" de diversas ideologias tradicionais e da ideologia da classe dirigente, é uma concepção fragmentada que, segundo o autor, "não pode ser erradicada e substituída senão por uma nova concepção, que se apresente intimamente fundida com um programa político e com uma concepção da história que o povo reconheça como expressões de suas necessidades vitais". Essa formação estaria ligada ao trabalho, à vida e à ciência.

A educação (em sentido amplo) desempenha um papel fundamental na construção e manutenção de uma concepção do mundo, tanto no nível de uma direção política que permita a elevação cultural (trabalhar na definição de sua própria filosofia e combater o senso comum), uma luta cultural, como no nível dos "aparelhos de hegemonia" (partidos, escolas ${ }^{7}$, igrejas, jornais, revistas) (GRAMSCI, 1995). A educação, nessa perspectiva, é, portanto, trabalho efetivo, ação positiva do homem, assim como é consciência positiva, humana, ou seja, práxis.

Ao tratar do papel da educação e, em particular, da educação escolar, em suas relações materiais, cabe analisar esse papel tendo em vista o desenvolvimento tecnológico, ou seja, o desenvolvimento da técnica e, em especial, das tecnologias digitais experimentado nas últimas décadas. Assim, escrever sobre essas tecnologias é partir de dois pressupostos: primeiro, a tecnologia é um dos instrumentos de produção, uma ferramenta que constitui o mundo cultural humano; segundo, sua evolução só pode ser analisada a partir do desenvolvimento da própria produção.

${ }^{7}$ Para Jesus (2005, p. 117), a escola em Gramsci não se restringe à instituição escolar, mas sofre uma ampliação, como ocorre com os conceitos de Estado e de intelectual, e passa a ser definida como "toda a organização que desenvolve cultura". 
Não há como negar o ápice atingido pelo desenvolvimento tecnológico na fase atual do capitalismo. No entanto, considerando a natureza de sua utilização, é necessário destacar dois momentos: a tecnologia, enquanto desenvolvimento das forças produtivas, voltada ao desenvolvimento econômico capitalista, e a tecnologia da informação, enquanto informação e formação ideológicas, que visa a formação e a constituição de consumidores de novo tipo.

Cabe salientar que, apesar da difusão e uso das tecnologias digitais continuar seletiva e restrita, assim como nas duas Revoluções Industriais anteriores, no contexto atual, o número de cidadãos atingidos, assim como a velocidade desse processo são ampliados, conduzindo à formação de novos consumidores e trabalhadores capacitados para uma produção cada vez mais rápida, inclusive da própria tecnologia.

Logo, há uma linha cada vez mais tênue entre esses dois momentos de uso das tecnologias digitais (força produtiva e informação). Castells (1999), ao analisar o uso das novas tecnologias e seus três estágios (automação de tarefas, experiências de uso e reconfiguração das aplicações), diferencia-os quanto ao modo de aprendizagem (usando ou fazendo), destacando que, enquanto as elites aprendem fazendo, "a maior parte das pessoas aprende usando e, assim, permanecem dentro dos limites do pacote da tecnologia". Assim como enfatiza que "a inovação tecnológica" depende das "condições específicas de cada sociedade" ou, como diria Marx, das condições objetivas em um determinado momento histórico.

Nesse sentido, o desenvolvimento da tecnologia, enquanto força produtiva, não estaria possibilitando o desenvolvimento da estrutura econômica e, consequentemente, de novas funções e novos usos, enfim, o desenvolvimento de novas relações de produção?

A partir da década de 1970 foram desenvolvidas várias análises em relação à sociedade capitalista e, mais especificamente, acerca do desenvolvimento tecnológico. Duas dessas grandes posturas podem ser assim definidas: para uma, tendo em vista a Revolução Tecnológica, a sociedade atravessou os portais da modernidade para a pós-modernidade, da industrial para a pós-industrial, assim, ao invés de uma sociedade capitalista teríamos uma sociedade informacional ou de informação. Outra afirma que, apesar das mudanças no processo de produção capitalista, com o advento das tecnologias digitais, ainda estamos sob a égide do modernismo e a humanidade estaria passando por um momento de crise no nível econômico, político e social.

Castells (1999, p. 24), tomando como ponto de partida o processo de transformação tecnológica, a que denomina "revolucionária", destaca que a opção metodológica de tomar a revolução da tecnologia da informação como ponto inicial não significa um "determinismo 
tecnológico", ou seja, não significa que "novas formas e processos sociais surgem em consequência de transformação tecnológica. É claro que a tecnologia não determina a sociedade".

Kumar (1997, p. 29; 37; 43-45) enfatiza que "a aceitação da importância crescente da tecnologia da informação, e mesmo de uma revolução de informação, é uma coisa, mas a aceitação da ideia de uma nova revolução industrial, de um novo tipo de sociedade, de uma nova era, é outra completamente diferente", uma vez que "o taylorismo continua a ser o princípio dominante", arrematando que a Tecnologia da Informação (TI), "com todas as tecnologias, foi escolhida e moldada de conformidade com certos e determinados interesses sociais e políticos". Sobre esse aspecto, Castells (1999a, p. 25) sinaliza que, como o paradigma tecnológico foi constituído principalmente na crise econômica dos EUA, na década de 1970, na tentativa de "assegurar a superioridade militar sobre os rivais soviéticos, em resposta a seu desafio tecnológico na corrida espacial e nuclear [...], seria tentador relacionar a formação desse paradigma tecnológico diretamente às características de seu contexto social”.

Ao negar essas condições objetivas que motivaram "uma reestruturação drástica do sistema capitalista em escala global", o autor sinaliza que, "embora haja uma coincidência histórica, [...] a emergência de um novo sistema tecnológico na década de 70 deve ser atribuída à dinâmica autônoma da descoberta e difusão tecnológica, inclusive aos efeitos sinérgicos entre todas as várias principais tecnologias (CASTELLS, 1999, p. 68). Contudo, sem querer desmerecer a importância do acaso no desenvolvimento histórico, a partir dos anos de 1970 vale salientar que a tecnologia, que começou a ser desenvolvida na década de 40, só pode vir a se manifestar quando as condições objetivas estavam postas, ou seja, a crise do capitalismo e a afirmação militar dos EUA.

Portanto, apesar de haver uma concordância com o autor acerca dessa característica especificamente humana de construir a todo instante a cultura material e espiritual nas sociedades capitalistas, essa construção tem sido dialeticamente acompanhada da exclusão de um número cada vez maior de pessoas, tanto em relação ao acesso à evolução tecnológica, quanto à manutenção dos postos de trabalho. O mundo nunca alcançou tamanho desenvolvimento em relação à qualidade de vida para a espécie humana, ao mesmo tempo, quando se fala em desenvolvimento humano, nunca houve tamanha dívida social. Enfim, o desenvolvimento das forças produtivas tem ocorrido às custas da exclusão cada vez maior dos trabalhadores graças à robotização e à informatização e, portanto, ao esvaziamento do espaço de trabalho humano. 
A esse respeito, Flecha e Tortajada (2000, p. 23) sinalizam que "o desenvolvimento dessa economia vem acompanhado por organizações mais democráticas em nível micro, e em nível macro, pela forte exclusão do mercado e da produção de grandes setores da população". A princípio poderia parecer contraditória a relação democracia-exclusão, no entanto, Gramsci (2007, p. 297) já anunciava que uma classe é mais hegemônica quando ela permite às classes adversárias se organizarem, ou seja, a classe no poder cria mecanismos que permitem à outra classe crer que ela pode ser incluída, desde que cumpra os requisitos mínimos. Hoje, um deles está no domínio das tecnologias digitais!

Vale salientar que, historicamente, ora o homem tem aprendido a se defender quando ameaçado, o que caracteriza o próprio processo de hominização, ora tem oprimido outro homem através do uso de instrumentos e das ideias. A robotização e a informatização são alguns desses instrumentos. Marques (2014, p. 34-36) aponta que, para Marx, a máquina "não é um meio de trabalho", ou seja, não é mais o homem que age sobre o objeto, mas é a maquinaria que se utiliza do trabalhador. Com a maquinaria, "o trabalhador é subjugado e passa a ser dominado por um poder que lhe é estranho, ou seja, um poder alienado". Segundo o autor, Marx vislumbrava "um cenário em que o trabalho adquire um potencial libertador, o que colocaria em xeque a dominação do capital”, conforme sinaliza Marx (2011, p. 941), "do nível geral da ciência e do progresso da tecnologia, ou da aplicação dessa ciência à produção". Nesse sentido, a tecnologia deveria ser mais uma expressão humana, mais um bem material produzido culturalmente pelo homem e ao qual todo homem deveria ter acesso.

Frigotto (2015, p. 220), contudo, ao analisar o desenvolvimento tecnológico nas sociedades capitalista, denuncia que "as novas tecnologias que combinam informação e microeletrônica dão, tanto ao capital produtivo quanto ao capital financeiro, enorme poder e mobilidade, permitindo desfazer-se de enormes contingentes de trabalhadores". Assim como cabe nesse processo "eliminar ou flexibilizar as leis que protegiam os empregados e instaurar processos de superexploração".

A partir do exposto, como pensar a propalada "crise" por que passam as sociedades, incluindo a "crise de paradigmas"? Mushakoji (1999, p. 196; 198) destaca que essa "é a crise dos diferentes paradigmas que levaram o processo de desenvolvimento global aos limites da sustentabilidade, ou talvez além deles"; e que paradigmas alternativos poderiam ter mudado a “estrutura do sistema mundial”, negando que a hegemonia é uma questão de poder. Por outro lado, Pearce (1996, p. 174-179; 181-182) sinaliza que um "novo paradigma consiste em novas maneiras de pensar sobre nós mesmo, nossa relação mútua e a sociedade em que vivemos" e que o novo paradigma, a "revolução das comunicações", permite que questionemos o "nosso 
conceito sobre a comunicação". Contudo, sinaliza o autor, um novo paradigma "não é um invento extraído do nada, mas uma resposta às condições cambiantes do mundo contemporâneo que puseram em primeiro plano a comunicação". Entretanto, ao não se questionar o desenvolvimento da comunicação na sociedade capitalista, pergunta-se: a chamada "revolução das comunicações" poderia ser realmente entendida como um "novo paradigma"?

A esse respeito, Flecha e Tortajada (2000, p. 22) sinalizam que, "para alguns talvez em uma visão apocalíptica, cabe falar de crise, para nós, de transformação" e arrematam: "não se deve confundir uma mudança no processo de produção com um a mudança no modo de produção. Nossa sociedade não é pós-capitalista, mas sim capitalista, embora agora se consigam os produtos graças à micro-eletrônica ou à biotecnologia". Dessa forma, não deveríamos falar de transformação, mas de mudança, assim, mudando-se as tecnologias (as forças produtivas na infraestrutura), estar-se-ia mudando, desejadamente, os paradigmas (as concepções na superestrutura), o que, como apontam os autores, não ameaça o modo de produção capitalista.

Portanto, se o que se está ocorrendo é tão somente uma mudança nos instrumentos no processo de produção, poder-se-ia falar em uma sociedade da informação (ou tecnológica)? Poder-se-ia falar em revolução tecnológica, em oposição a uma revolução industrial? Se o capitalismo está entrando em uma nova fase e com ele a superestrutura está se alterando, de forma a dar sustentabilidade ao novo processo de produção, poder-se-ia falar de uma "crise de paradigmas" ou seria mais adequado dizer mudança de paradigmas? Essa é uma questão que envolve toda uma concepção do mundo e, nesse sentido, passa-se a questionar o lugar dessas análises no seio dessa sociedade. Ao afirmarem uma "crise de paradigmas", essas análises não estariam reafirmando uma visão liberal (neoliberal) que, em última instância, atende às necessidades do novo processo de produção capitalista?

Misturar ou separar um paradigma da base econômica que o justifica é fazer afirmativas como: um paradigma é uma questão de escolha! Por sua vez, afirmando uma crise, afirma-se que as concepções, os valores, têm que mudar tendo em vista as novas necessidades do capital, reafirmando, em última instância, a nova ordem mundial. Como afirma Gramsci (2007, p. 48), a aparente separação entre o econômico e o político na ideologia, assim como na prática, é um efeito do modo de produção capitalista.

Seguindo nessa linha de raciocínio, Mushakoji (1999, p. 203; 207) afirma que "novos paradigmas têm que ser gerados por uma coligação anti-hegemônica que, se formada, talvez forneça a base para uma nova ordem mundial que supere a atual crise global [e que] tal 
coligação anti-hegemônica só pode ser formada se diversos grupos forem bem sucedidos em compartilhar valores comuns apesar da diferença de suas posições epistêmicas", a que ele denomina "humanismo existencial".

Por fim, Mushakoji (1999, p. 195), ao analisar a influência do processo de ocidentalização nas sociedades não ocidentais, destaca que as regiões não ocidentais são ricas em "paradigmas alternativos" devido a seu senso comum derivado de diversos cruzamentos de diferentes comunidades epistêmicas. Isso não significa que sua população tenha ficado imune à ocidentalização, mas que seguiram consumindo tecnologias, conceitos de organização social e política e novos valores e estilos de vida, sem ter, na maioria das vezes, consciência. O que não pode ser relegado a segundo plano!

Frente ao exposto, cabe-se perguntar: que papel é atribuído às inovações tecnológicas na educação escolar frente às necessidades do capital?

\section{Inovações tecnológicas na educação: o Livro Verde}

Em cada momento histórico, a classe dominante define o tipo de sociedade, o tipo de educação, de ideologia que deseja difundir, enfim, a superestrutura fornece o cimento ideológico necessário à sua permanência. Na atualidade, nesse quadro da chamada "crise dos paradigmas", o papel dominante que se atribui à educação não poderia ser outro que não o de reafirmar a importância de estarem todos adaptados, capacitados, prontos para saberem manipular, manusear e consumir. Nesse sentido, não faltam documentos que, partindo de uma análise teórica sobre as tecnologias digitais, apontem sua abrangência em todo mundo e seu impacto econômico-social.

Dentre outros autores, Flecha e Tortajada (2000, p. 21-22) analisam as tendências que apontam “como será e como deveria ser a educação nos próximos anos”. Uma delas se refere às competências requeridas tendo em vista as mudanças socioeconômicas e os desafios para a educação, considerando as mudanças constantes em nível sociocultural. A outra propõem a educação do novo milênio, analisando as tendências que transformem "dificuldades em possibilidades", que desenvolvam o "conceito de aprendizagem dialógica" (superando as "concepções construtivistas" e objetivando "a igualdade, a solidariedade, a aprendizagem instrumental de conhecimentos e habilidades e a transformação") e visem à "transformação de escolas em comunidades de aprendizagem", como forma de "superar os processos de exclusão". 
Ora, acerca dessas tendências, cabe-se perguntar: a exclusão não estaria na essência do próprio processo de desenvolvimento tecnológico capitalista, ou seja, no desenvolvimento da base material: da técnica, da propriedade privada dos instrumentos de produção e reprodução social, na divisão social do trabalho, nas relações sociais de produção? E, da educação escolar, não estariam sendo exigidas as competências e habilidades necessárias a esse desenvolvimento tecnológico?

No Brasil, o denominado Livro Verde (2000) é um exemplo elucidativo dessa exigência e merece ser retomado, considerando sua importância na disseminação da ideologia do lema "aprender a aprender", presente em diversos documentos oficiais e na produção teórica. A adesão a esse lema, sinaliza Duarte (2000, p. 42), “implica necessariamente a adesão a todo um ideário educacional afinado com a lógica da sociedade capitalista contemporânea" e, diretamente relacionado ao referido lema, na implementação do chamado "empreendedorismo educacional"8. Assim como tem servido de orientação a professores, tanto na formação inicial em Cursos de Licenciatura e nos Programas de Pós-Graduação, como na capacitação de professores para atuarem na educação a distância - EAD.

Esse artigo ater-se-á aos capítulos 1 e 4, em que Takahashi (2000, p. 5-9) apresenta, respectivamente, A sociedade da informação e a Educação na sociedade da informação. No capítulo 1, o documento revela que o Brasil dispõe "dos elementos essenciais para a condução de uma iniciativa nacional rumo à sociedade da informação. E [...] prestar significativa contribuição para resgatar a sua dívida social [...] e manter uma posição de competitividade econômica no cenário internacional".

Takahashi (2000, p. 5-9) aponta as transformações que o país deve promover visando uma "inserção favorável nessa onda" e as oportunidades e os riscos a que estão sujeitos os países que caminham "rumo à sociedade da informação, competindo a cada um encontrar sua rota e suas prioridades". Portanto, dessa onda, "sociedade da informação", não haveria como escapar! Ou seja, essa não é uma sociedade constituída com o desenvolvimento e a expansão do conhecimento, mas uma sociedade que, ao mergulhar na onda das tecnologias digitais, delas deve se apropriar, se adaptar, sob o risco de ficar à margem do desenvolvimento mundial, ou seja, "à margem do desenvolvimento da nova economia [...]. Nesse contexto, é prioritário o desenvolvimento e a implantação da Internet de nova geração no País".

Cabe também destacar que o documento é atravessado por conceitos mercadológicos (competitividade, produtividade, empreendedorismo, etc.), indicando o caminho que um país

\footnotetext{
${ }^{8}$ A empregabilidade, juntamente com o trabalho e a profissionalização, constitui, na atualidade, em elemento do empreendedorismo educacional. A esse respeito ver Wolf (2014) e Melo (2010).
} 
"em desenvolvimento" deverá seguir em tempos de globalização. No item "Objetivo do Programa Sociedade da Informação", conclama os diferentes parceiros para essa empreitada, setor privado (o mais interessado), governo e sociedade civil, destacando a importância das universidades e demais entidades educacionais para o êxito do Programa e definindo o calendário e os passos para o desenvolvimento do Programa, bem como sua estrutura organizacional. De forma aparentemente compensatória, também enfatiza a importância de valorizar e preservar os conteúdos e a identidade cultural (TAKAHASHI, 2000, p. 8).

A educação mais uma vez surge, portanto, como a grande salvadora da pátria. À educação caberia, segundo Takahashi (2000, p. 6-7), capacitar para que os "consumidores estejam conectados às redes digitais e capacitados para operá-las adequadamente". Essa capacitação não deve, assim, se restringir à formação para o trabalho, mas contribuir na constituição de novos consumidores. Nessa "onda", alunos e educadores devem adequar-se às novas tecnologias, devem adquirir "competência para transformar informação em conhecimento".

No capítulo 4, o documento ressalta que "a educação é o elemento-chave na construção de uma sociedade baseada na informação, no conhecimento e no aprendizado", seguindo o lema aprender a aprender (TAKAHASHI, 2000, p. 45) e apresentando os "novos meios de aprendizagem", com destaque para a “educação à distância” do Ensino Médio à pósgraduação (incluindo a aceleração de cursos) e em qualquer área (saúde, transporte, etc.).

Nas tecnologias da informação coloca-se o papel de democratização dos processos sociais e participação social, entretanto, esse papel fica bastante comprometido, visto que a “instalação de uma infraestrutura nas escolas e outras instituições de ensino no país” é bastante onerosa e que "os países em desenvolvimento enfrentam vários problemas para fazer face a esse desafio". Por outro lado, em relação ao "desafio da formação tecnológica", o documento, seguindo o viés de formar consumidores, sinaliza que "há argumentos no sentido de que, para países em desenvolvimento, a capacidade de absorver novas tecnologias e de colocá-las em aplicação é tão ou mais importante do que a capacidade de gerar essas tecnologias" (TAKAHASHI, 2000, p. 48), apontando a dependência dos países em desenvolvimento das tecnologias de países desenvolvidos e a necessidade de capacitar para a atuação prática.

Flecha e Tortajada (2000, p. 24-25) afirmam que, em educação, a dualização, ou polarização social, "é concretizada no fato de que a sociedade da informação prioriza o domínio de certas habilidades" e que as pessoas que não dominam tais habilidades "correm o risco de ficar excluídas dos diferentes âmbitos da sociedade informacional". E apontam, assim 
como enfatizado no Livro Verde, que a solução está em que educadores e educadoras conheçam "a sociedade em que vivemos e as mudanças geradas para potencializar não apenas as competências dos grupos privilegiados, mas também as competências requeridas socialmente, porém a partir da consideração de todos os saberes". Entretanto, em relação a essas habilidades e competências, não questionam o tipo de sociedade para a qual estão sendo gestadas, mas o desconhecimento sobre a teoria da sociedade da informação.

Neste contexto, segundo Frigotto (2015, p. 220-221), "cunha-se a ideologia da revolução científica e tecnológica que tem como síntese a tese da sociedade do conhecimento. Dentro de uma realidade em que não só a ciência, mas também a informação, está cada vez mais monopolizada privadamente"; e dissemina-se "a ideia de que todos podem acessar o conhecimento e, portanto, também não há mais classes sociais". Com o avanço da técnica, "no contexto da produção flexível, amplia-se a substituição de trabalhadores por capital morto e extinção e a flexibilização de direitos, não cabe garantir o direito ao emprego. Trata-se de educar para a empregabilidade e esta depende de cada um". Assim, o lema "aprender a aprender" atinge sua excelência!

No que se refere à educação de jovens e adultos, os documentos da V CONFINTEA apontam que as competências e as habilidades devem estar relacionadas às reais necessidades e às possibilidades de um espaço de trabalho real e não de um espaço idealizado, visto que não há perspectiva de trabalho para todos. Entretanto, tal afirmação não pode negar aos grupos excluídos o acesso ao conhecimento acumulado, delegando a esses grupos uma educação de segunda ordem e ampliando a exclusão!

Azevedo (2011, p. 152), ao tratar da expansão da internet e do ensino superior a distância, destaca que há "uma coincidência de foco nas classes C, D e E que nos dá uma perspectiva clara com relação ao futuro e com respeito aos desafios que este futuro nos coloca hoje", contudo questiona-se: se os sujeitos que estão chegando ao ensino superior pertencem às classes $\mathrm{C}, \mathrm{D}, \mathrm{e} \mathrm{E}, \mathrm{o}$ acesso ao ensino presencial caberia às $\mathrm{A}$ e $\mathrm{B}$ ? Tal fato não ampliaria a exclusão e a desigualdade social? Em relação à educação superior a distância, a Resolução CES/CNE $n^{\circ}$ 01/2016 busca dirimir tais efeitos através de "políticas de acesso, acompanhamento e avaliação compatíveis", de forma a garantir "a participação democrática nos processos de ensino e aprendizagem em rede".

Flecha e Tortajada (2000, p. 28; 31; 33) defendem um modelo de educação que passe da cultura da queixa para a cultura da transformação e apontam que, na sociedade da informação, a orientação comunicativa e dialógica é a única forma de superar a "crise da escola" e de permitir a participação "mais ativa e de forma mais crítica e reflexiva na 
sociedade”. Os autores sinalizam que essa mudança na educação não é uma proposta apenas capitalista, visto que a teoria do capital humano também parte "da premissa de que a qualificação formativa da mão-de-obra supunha um capital que podia ser reinvestido no processo produtivo".

Por fim, se se toma como premissa que a "crise na escola" se deve à transformação na base material e que não há espaço no mercado de trabalho para todos os "qualificados", tal qualificação termina por formar um exército de reserva e consumidores de novo tipo. Logo, pergunta-se: de que educação, de que formação, está se falando?

\section{Considerações finais}

Os questionamentos atuais acerca da informação e da tecnologia têm se restringido à sua aplicabilidade, ao seu uso e ao aumento da exclusão da maioria da população do acesso às tecnologias digitais. Nessa perspectiva, a sociedade é percebida como algo dado e a luta pela sua transformação cede espaço à luta de todos (governo, sindicatos, sociedade civil, ONGs) para incluir, nesta sociedade, um maior número de pessoas, de consumidores. Nessa trajetória, a educação, mais especificamente a escola, é chamada a exercer esse papel de adaptação.

Partindo do pressuposto de que a sociedade ainda caminha sob a égide do modo de produção capitalista, a chamada "crise de paradigmas" traduz, na sua essência, uma mudança na base material, nos instrumentos de produção, com o advento das tecnologias digitais, o que justifica uma mudança na superestrutura (do qual é um reflexo), ou seja, nos paradigmas necessários a esse modo de produção. Nesse sentido, a organização do Livro Verde é fruto dessa mudança histórica na superestrutura, visando a reorganização da educação, da escola.

Por fim, vale salientar que a questão não está em diabolizar ou divinizar as tecnologias digitais, mas em questionar o seu uso como ferramenta de dominação e exclusão e o papel dos educadores, enquanto intelectuais, nesse processo.

\section{REFERÊNCIAS}

AZEVEDO, W. Menos pode ser mais: por que precisamos de tecnologias mais simples e menos sofisticadas para a EAD. In: DINIZ, E. C., VAN DER LINDEN, M. M. G., FERNANDES, T. A. (Orgs.). Educação a distância: coletânea de textos para subsidiar a docência online. João Pessoa: Editora da UFPB, 2011. Disponível em:

http://biblioteca.virtual.ufpb.br/files/educaaao_a_distancia_coletanea_de_textos_para_subsid iar_a_docancia_online_1330089617.pdf. Acesso em: 15 ago. 2016. 
BRASIL. Conselho Nacional de Educação. Resolução CNE/CES n ${ }^{\circ} 1$, de 11 de março de 2016. Disponível em:

http://download.inep.gov.br/educacao_superior/avaliacao_institucional/ead/legislacao_norma s/resolucao_n_1_11032016.pdf. Acesso em: 05 maio 2016.

CASTELLS, M. Prólogo: a rede e o ser. In: CASTELLS, M. A sociedade em rede. Rio de Janeiro, Paz e Terra, 1999a.

CASTELLS, M. A revolução da tecnologia a informação. In: CASTELLS, M. A sociedade em rede. Rio de Janeiro, Paz e Terra, 1999b.

DUARTE, N. Vigotski e o "aprender a aprender": crítica às apropriações neoliberais e pósmodernas da teria vigotskiana. Campinas (SP): Ed. Autores Associados, 2000.

FLECHA, R.; TORTAJADA, I. Desafios e saídas educativas na entrada do século. In: INBERNON, F (org). A educação no século XXI: os desafios imediatos. Porto Alegre, Artmed, 2000.

FRIGOTTO, G. A produtividade da escola improdutiva 30 anos depois: regressão social e hegemonia às avessas. Revista Trabalho Necessário. Ano 13, n. 20, 2015. Disponível em: www.uff.br/trabalhonecessario. Acesso em: 10 nov. 2016.

GRAMSCI, A. Cadernos do Cárcere. v. 3, 3. ed. Rio de Janeiro: Civilização Brasileira, 2007.

GRAMSCI, A. Concepção dialética da História. 10. ed. Rio de Janeiro: Ed. Civilização Brasileira, 1995.

GRAMSCI, A. Os intelectuais e a organização da cultura. 7. ed. Rio de Janeiro: Ed. Civilização Brasileira, 1989. (Perspectivas do homem. Série Filosofia, v. 48).

KUMAR, K. Da sociedade pós-industrial à pós-moderna. Rio de Janeiro, Jorge Zahar, 1997.

MARQUES, R. M. Intelecto geral e polarização do conhecimento na era da informação: o Vale do Silício como exemplo. 2014. 254 f. Tese (Doutorado em Ciência da Informação) Universidade Federal de Minas Gerais, Belo Horizonte, 2014. Disponível em:

www.bibliotecadigital.ufmg.br/.../intelecto_geral_e_polariza_o_do_conhecimento_na_... Acesso em: 30 out. 2016.

MARX, K. Grundrisse. São Paulo: Boitempo, 2011.

MARX, K. Marx. 2. ed. São Paulo: Ed. Abril Cultural, 1978. (Os Pensadores)

MELO, A. de. O projeto pedagógico da Confederação Nacional da Indústria para a educação básica nos anos 2000. Orientadora: Professora Doutora Lígia Regina Klein. 2010. Tese (Doutorado em Educação) - Universidade Federal do Paraná, Curitiba, 2010. Disponível em: www.ppge.ufpr.br/teses\%20d2010/d2010_Alessandro\%20de\%20Melo.pdf. Acesso em: 06 nov. 2016. 
MUSHAKOJI, K. Em busca de uma aliança anti-hegemônica. In: HELLER, A. A crise dos paradigmas em ciências sociais e os desafios para o século XXI. Rio de Janeiro, Contraponto, 1999.

PEARCE, W. B. Novos modelos e metáforas comunicacionais: a passagem da teoria à prática, do objetivismo ao construcionismo social e da representação à reflexividade. In: SCHNITMAN, D. C. Novos paradigmas, cultura e subjetividade. Porto Alegre: Artmed, 1996.

TAKAHASHI, T. (Org.). A sociedade da informação. Livro Verde. Brasília: Ministério da Ciência e Tecnologia, 2000.

V CONFINTEA. La educación de personas jóvenes e adultas en América Latina y el Caribe. Prioridades de acción en el siglo XXI - UNESCO - CEEAL - CREFAL - INEA. Santiago de Chile, Mayo 2000.

WOLF, L. A pedagogia vai ao porão: a pedagogia empresarial e empreendedora e o processo de naturalização do social. Orientador: Prof. Dr. Alessandro de Melo. 2014. Dissertação (Mestrado em Educação) - Universidade Federal do Paraná, Curitiba, 2014. Disponível em: www.ppge.ufpr.br/teses/M14_Luciani\%20Wolf.pdf. Acesso em: 05 nov. 2016.

\section{Como referenciar este artigo}

BAPTISTA, Maria das Graças de Almeida; PALHANO, Tânia Rodrigues; DINIZ, Ercules Laurentino; SILVA, Genilson José da. Inovações tecnológicas, educação e necessidades do capital. Revista Ibero-Americana de Estudos em Educação, Araraquara, v. 15, n. 1, p. 289304, jan./mar. 2020. e-ISSN: 1982-5587. DOI: https://doi.org/10.21723/riaee.v15i1.12710

Submetido em: 30/06/2019

Revisões requeridas: 10/08/2019

Aprovado em: 20/10/2019

Publicado em: 02/01/2020 